\title{
The contribution of work characteristics and risk propensity in explaining pro-social rule breaking among teachers in Wakiso District, Uganda
}

\begin{tabular}{|c|c|}
\hline \multicolumn{2}{|c|}{$\begin{array}{l}\text { Authors: } \\
\text { Waweru I. Kahari }^{1} \\
\text { Kyakuha Mildred }^{1} \\
\text { Nsereko Micheal }^{1}\end{array}$} \\
\hline \multicolumn{2}{|c|}{$\begin{array}{l}\text { Affiliations: } \\
\text { 'Department of Human } \\
\text { Resource Management, } \\
\text { Makerere University Business } \\
\text { School, Uganda }\end{array}$} \\
\hline \multicolumn{2}{|c|}{$\begin{array}{l}\text { Corresponding author: } \\
\text { Waweru Kahari, } \\
\text { ebrahimkahari@gmail.com }\end{array}$} \\
\hline \multicolumn{2}{|c|}{$\begin{array}{l}\text { Dates: } \\
\text { Received: } 24 \text { Apr. } 2016 \\
\text { Accepted: } 11 \text { Mar. } 2017 \\
\text { Published: } 25 \text { July } 2017\end{array}$} \\
\hline \multicolumn{2}{|c|}{$\begin{array}{l}\text { How to cite this article: } \\
\text { Kahari, W.I., Mildred, K., \& } \\
\text { Micheal, N. (2017). The } \\
\text { contribution of work } \\
\text { characteristics and risk } \\
\text { propensity in explaining } \\
\text { pro-social rule breaking } \\
\text { among teachers in Wakiso } \\
\text { District, Uganda. SA Journal } \\
\text { of Industrial Psychology/SA } \\
\text { Tydskrif vir Bedryfsielkunde, } \\
\text { 43(0), a1368. https://doi. } \\
\text { org/10.4102/sajip.v43i0.1368 }\end{array}$} \\
\hline \multicolumn{2}{|c|}{$\begin{array}{l}\text { Copyright: } \\
\text { @ 2017. The Authors. } \\
\text { Licensee: AOSIS. This wo } \\
\text { is licensed under the } \\
\text { Creative Commons } \\
\text { Attribution License. }\end{array}$} \\
\hline \multicolumn{2}{|l|}{ Read online: } \\
\hline 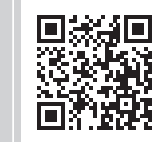 & $\begin{array}{l}\text { Scan this QR } \\
\text { code with your } \\
\text { smart phone or } \\
\text { mobile device } \\
\text { to read online. }\end{array}$ \\
\hline
\end{tabular}

Orientation: This study explored the mechanisms that drive pro-social rule breaking among teachers in Ugandan private secondary schools.

Research purpose: The main aim of this study was to examine the contribution of work characteristics and risk propensity in promoting pro-social rule breaking among teachers in one of the Ugandan districts that has a high number of private schools.

Motivation for the study: As there is a scarcity of research on pro-social rule breaking in Uganda, this study sought to explore the concept and shed light on the mechanisms that influence this.

Research design, approach and method: A quantitative research process formed the basis for this study. Two hundred and forty-two teachers from 15 private secondary schools in Wakiso District formed the targeted sample size. A response rate of $87 \%$ was registered. A hierarchical regression analysis was conducted in order to assess the influence of each of the variables on the dependent variable, by using Statistical Package for Social Sciences.

Main findings: The regression results showed that work characteristics were a statistically significant predictor of pro-social rule breaking, but risk propensity was not. The results finally showed that there was no moderation effect of risk propensity on the relationship between work characteristics and pro-social rule breaking.

Practical implications: The schools should expect more pro-social rule-breaking tendencies when the tasks given to the teachers are complex and when the teachers operate with autonomy. The environment in which the private secondary school teachers in Uganda work, motivates them to sometimes break rules in a bid to perform better or minimise the complexity associated with work.

Contribution: This study expands on current theoretical knowledge on pro-social rule breaking and provides insights into the key drivers of the same among private secondary school teachers in the Ugandan context.

\section{Background}

The performance of an individual employee and the organisation, in general, will be influenced by some critical decisions an individual employee makes at the point of executing his or her tasks. Employees have at times enhanced the performance of their organisations by going against the rules and policies, a concept known as pro-social rule breaking (Phil, Bryant, Davis, Hancock \& Vardaman, 2010). The concept refers to a positive behaviour that is motivated by the love and concern for an organisation that entails intentional violation of formal policies and regulations in a bid to promote the welfare of the organisation or any of its stakeholders (Dahling, Chau, Mayer \& Gregory, 2012).

Uganda provides an interesting context to examine the concept of pro-social rule breaking for a number of reasons. One of such reasons is an environment where not much scholarly work examining the concept has been performed. On the other hand, the work environment in the country also has some interesting characteristics that make pro-social rule-breaking behaviour important. Notably, the owners of the private sector firms that dominate the economy enjoy the freedom to control their labour force without much interference from government and labour unions. For instance, they have a free hand in setting the salaries because as of now there is no official minimum salary, the labour unions are weak and the labour courts are almost inactive, 
therefore making the labour laws implementation difficult (Ssanyu, 2013). These weaknesses allow some of the firms to place too much pressure on employees, subjecting them to long-term discomfort, which can be detrimental to their health, and having them justify their worth if they are to still remain in employment. As a means of survival in such an environment, the employees may have to demonstrate more proactive behaviours (Caza \& Cameron, 2008), one of which may be pro-social rule breaking as it has been discovered that such a behaviour has at times achieved positive results in such terms as improved performance or introducing notable changes that appeal to the employers (Youli, Xixi \& Xi, 2014).

Private secondary schools represent one of such business setups that operate in the Ugandan context, which has attracted a huge investment by local players. The statistics show that private schools outnumber the government schools (Uganda Ministry of Educations and Sports, 2014). It is also a business venture that is characterised by stiff competition because to attract students and by extension to realise favourable earnings, the schools have to produce students with good grades in the national exams both at Ordinary and Advanced Levels. Other secondary achievements in sports and other cocurricular activities also give schools an added advantage. For the said success to be realised, the role of the teachers is vital. It is therefore expected that schools should provide social, emotional resources to enable the teachers to perform their duties effectively (Rothmann \& Welsh, 2013). On the contrary, however, like in other private firms, teachers in many Ugandan private schools operate under intense pressure resulting from being assigned heavy teaching work load and at times allocated little resources in terms of teaching facilities and materials, yet expected to produce good performance. Further, the teachers are assigned different roles apart from teaching, which may include supervising students during music and drama festivities, study tours, school functions and other incidental assignments (Sekiyivu, 2013). In the process of executing their duties, however, the teachers are faced with situations where strict following of the rules would either affect their health, performance or lead to a negative impact on their schools.

Surprisingly, however, despite the said environment, there are some major private schools that have always emerged the top in national exams, thus beating the government schools (Uganda Ministry of Educations and Sports, 2014). After the results are released, public inquiry by media and other interested stakeholders is performed, especially on top candidates and the teachers whose students emerge top in the subjects they teach. The private schools receive a considerable interest possibly in order to justify the fees they charge. During such inquiries, it has emerged that the outstanding teachers have shown unique behaviours that enable them to overcome the challenges that they may have to face in their workplace (Naluwemba, Sekiwu \& Okwenje, 2015). While the term pro-social rule breaking has not been used during the various narrations, it has been quite evidenced that it is one of the behaviours that has helped the outstanding performers achieve good results. The teachers have used such terms as 'going against the grain', or 'devising their own mechanism' to explain their strategies (Naluwemba et al., 2015), which gives a clear pointer that they are possibly involved in pro-social rule breaking. This, therefore, provides a good opportunity for a study to be conducted to examine the tendency of pro-social rule breaking among teachers in private secondary schools.

As to how pro-social rule breaking can be ignited, work characteristics theory can be informative (Bryant, Davis, Hancock \& Vardaman, 2010). The theory prescribes work design principles which can be assessed in regard to the degree of employee autonomy, skill variety, task complexity, feedback and task significance (Hackman \& Oldham, 1976). The way jobs are designed may at times present an employee with a dilemma, especially when the task is complex because of unanticipated outcomes. In attempting to accomplish such tasks, an employee may choose to ignore or defy some rules and procedures, thus engaging in pro-social rule breaking.

An individual's attitude towards risk taking is another possible explanation why people engage in pro-social rule breaking. Notably, people are either naturally different, or may assess the prospects of taking a given risk, thus the differences in risk taking propensity (Nicholson, FrentonO'Creevy, Soane \& Willman, 2002). People with a higher level of risk propensity are likely to engage in behaviours that challenge organisational policies, rules and guidelines when they deem it necessary. This is so because such people are hopeful that the outcome would be positive, or that there are gains associated to their choice of action. On the other hand, people whose propensity towards risk is low, are unlikely to break rules especially when the outcomes are unclear.

In this study, an inquest was made to assess the drivers of pro-social rule-breaking behaviour among private school teachers in the Ugandan context, which appear to partly explain why performance in some of these schools has been good, but which has so far attracted little attention from scholars. This study was performed with the aim of examining the role that works characteristics and individual personal differences in regard to risk taking play in explaining prosocial rule breaking.

\section{The purpose of the study}

This study sought to establish the relationship between work characteristics and risk propensity with an aim of establishing the mechanisms that drive pro-social rule breaking among teachers of secondary schools in Wakiso District. This is one of the districts that has a high population of private secondary schools in Uganda, where some of the schools that have been outstanding in national exams, are found.

\section{Research objectives}

The objectives of the research are to examine the relationship between work characteristics and pro-social rule breaking, to examine the relationship between employees' risk propensity 
and pro-social rule breaking and to examine the moderating effect of work characteristics and risk propensity on prosocial rule breaking.

\section{Significance of the study}

The studies examining pro-social rule breaking in the Ugandan context appear to be sparse. This study, therefore, adds to the scholarly work that has contributed to the literature on the concept of pro-social rule breaking.

The study will also be important to the schools examined on the concept of pro-social rule breaking. Other future scholars interested to undertake a similar study may find this work as a useful literature review source.

Furthermore, schools within Uganda and Africa can benefit, because this study's findings can set the stage for the establishment of a set of guidelines to improve overall school health.

\section{Literature review \\ Pro-social rule breaking}

There is a large volume of organisational literature that has dealt with the negative aspect of rule breaking at work. However, there have emerged a number of studies that have made inquiries on the positive aspect of rule breaking by employees. One such contribution was made by Morrison (2006), who coined the term pro-social rule breaking to describe the instances where an employee deliberately goes against a formal organisational policy, regulation or prohibition in a bid to promote the welfare of the organisation or one of its stakeholders. Such violation of a rule is thus instrumental in helping the organisation overall. The author went ahead to argue that such a violation may be viewed from three aspects where the aim would be to help the employee in question more efficiently perform their work duties, to help a fellow employee or to improve customer service (Afshar \& Doosti, 2015).

In their contribution, Vardaman, Gondo and Allen (2014) demonstrated the importance of having people who demonstrate pro-social rule-breaking behaviour by arguing that regardless of the fact that organisational rules are aimed to be in line with the organisational goals, employees are sometimes in a situation where following a given rule may be costly to an organisation. For example, where a rule of saying that goods sold are never returned, and a sales person follows this to the letter, an organisation may lose a key customer, and as a means of avoiding this, the salesperson may decide to break such a rule.

Dahling et al. (2012) added that pro-social rule breaking is a form of constructive deviance that entails breaking rules for the right reasons. Notably, the organisational life reality places employees in scenarios where they have to make choices to either follow the rules or to deviate in the interest of effectively responding to the demands from customers, co- workers or their tasks themselves. As such, it has been argued that at times an option to break the rules is more optimal. Such an argument deemed reasonable, especially when the employee's contribution and performance are important when performance appraisal is performed. There are situations where an organisation may later discover that a given rule is well beyond its time and require that it is dropped after a series of positive results arising from breaking of such a rule by the employees.

Further, Youli et al. (2014) indicated that as a result, prosocial rule breaking can be instrumental in improving the efficiency of employees, attracting and retaining customers and building social capital, which is enhanced through helping co-workers. Such positive outcomes are desirable because they contribute to the overall progress of an organisation and enhance the achievement of the set organisation. This, therefore, provides an interesting insight as to how far an employee can be given discretion of handling their tasks.

From the analysis of what constitutes pro-social rule breaking, it is possible to deduce that such behaviours are not contrary to some management principles, such as result-oriented management (Armstrong \& Taylor, 2012), management by exemption and the principles of job autonomy. When implementing such principles, employees are given space to exercise various alternatives and continuously learn, a process that at times entails deviating from the norm. This has received a strong backing from the positive organisational scholarship approach that has emphasised such behaviour would be instrumental for both the organisation's and the employees' well-being (Caza \& Cameron, 2008).

\section{Risk propensity and pro-social rule breaking}

The concept of risk entails taking chances with hope that the outcome would be favourable, although being aware they are not certain that the outcome may be negative. Individuals are said to engage in risk taking, but their level of doing so differs. This difference is what has come to be known as risk propensity (Nicholson et al., 2002).

Out of interest in expounding the concept of risk propensity, a number of views have emerged over time. One view is explained by the prospect theory, which is associated with the works of Kahneman and Tversky (1979). This theory proposes that risk taking is dependent upon a situation and the presumed prospects at a given time. A person, according to the theory, is likely to be risk averse when his or her belief that he or she is contented with a situation and be more risk taker when he or she feels that he or she is at a loss. Thus, a clear analysis of the theory is that a particular person can at different times demonstrate different levels of risk propensity. While the argument is supported, because at times a person takes more caution in different situations, the theory's weakness is as to why different people almost in a similar situation would demonstrate varied degrees of risk propensity. 
Another perspective advanced the view that risk propensity was one of the two major components that elaborate the concept of risk, the other one being risk perception (Sitkin \& Pablo, 1992). In this regard, risk propensity was viewed as a union between dispositional tendencies, cognitive inputs and past experience. Thus, a person's risk taking level can be taken as an accumulation of behaviours, mental beliefs and what happens over time in the life of an individual. Thus, risk propensity is the tendency of a person to either take or avoid risk. Risk perception, on the other hand, was viewed as the feeling that one has, before undertaking risk, that a given move is more risky than another.

Nicholson et al. (2002) identified key dimension of risk propensity to cover two major features, namely specific and general. The scholars felt that an individual can demonstrate more of risk-taking behaviour in one aspect, be it physical such as health and safety risk, lifestyle, such as recreational and social risk, or livelihood, such as career and financial risk. In general, regarding risk propensity, the focus is on overall risk taking. This description will be used for the purpose of this study.

In this study, we argue, based on the prospect theory, that teachers with a high degree of risk taking, given the anticipated positive outcomes, are likely to demonstrate a high possibility of being engaged in pro-social rule breaking than the employees with a low risk propensity. Furthermore, a person who embarks on taking risk has a preconceived belief that taking a risk would amount to a positive gain (Kahneman \& Tversky, 1979). Given the fact that pro-social rule breaking, is a deliberate action which motive is to help an organisation or its key stakeholders, it is possible to argue that an employee with high risk propensity is also likely to demonstrate high rate of pro-social rule-breaking behaviour.

Di Mauro et al. (2011) also provides a strong case that points towards a relationship between risk propensity and pro-social rule breaking. These authors attempted to demonstrate what motivates different categories of employees in different sectors to exhibit more risk taking tendencies than others. In reference to the prospect theory, the authors argued that such employees as teachers or civil servants, who have a fixed income, may demonstrate lower levels of risk propensity than other people, for example, salespersons. In qualifying their argument, the authors indicated that the survival and earnings of such people as salespersons heavily rely on their contribution and performance matters. This makes such employees ready to take risks that may inculcate defying set rules, as demonstrated by the examples that pro-social rule breaking may be performed to advance customer service. Because an improved customer service would entail attracting and retaining more customers and thus improved sales, it is possible to infer that risk propensity predicts the level of pro-social rule breaking.
Another indication that shows the possibility of risk taking being an antecedent of pro-social rule breaking would be to examine what the risk takers do. In respect to this, Block, Sandner and Spiegel (2009) observed that risk takers in an organisation are involved in being creative and trying to come up with the means and methods of improving performance. Because such creativity can entail going beyond what is normally the practice or expected norm, we can argue that this is a pointer that the more risk an individual takes, the more they are likely to exhibit pro-social rule breaking.

Further, the literature linking risk propensity and innovative behaviours also provides a ground to argue that people with a high level of risk propensity are also likely to be involved in pro-social rule breaking. In respect to this, an insight is provided in the work of Hentschke (2005) whose aim was to demonstrate the relationship between risk propensity and innovation in organisations. The scholar emphasised that creative behaviours are important in promoting innovations. Such behaviours entail challenging the existing status quo of an organisation. Thus, the scholar argues that this is mainly performed by people with a high risk propensity as they are the ones who have high hopes that their defiance position would lead to positive outcomes. From that view, we can borrow from the aspect of challenging the status quo as defying the set rules and policies with an aim of getting work performed well or better organisational outcomes, to mean pro-social rule breaking.

One key study that attempted to directly assess the relationship was performed by Morrison (2006). The findings of that study indicated that risk propensity was vital in predicting pro-social rule-breaking behaviours. In the study, the participants who were found to be likely pro-social rule breakers were the ones who had a high level of risk propensity.

There are still other studies that provide convincing arguments that support the view that people with a higher risk propensity are more likely to be involved in pro-social rule breaking. For instance, according to Alshut (2014), entrepreneurial leaders are considered very instrumental in promoting the performance of an organisation. To be entrepreneurial, the scholar pointed out that this would involve risk taking and sometimes acting against the established norms. Because the aim of such a deviance is for the good of an organisation, it fits into the category of prosocial rule breaking. Therefore, according to the argument, leaders who possess a high risk propensity are most likely to occasionally exhibit pro-social rule-breaking behaviours.

Therefore, it is possible to deduce that people with high risk propensity are more likely to demonstrate pro-social rulebreaking behaviour.

\section{Work characteristics and pro-social rule breaking}

The concept of work characteristics is mainly examined from the job characteristics theory of Hackman and 
Oldham (1976). The theory posits that there are five job characteristics which show the design of a job. The five characteristics include job variety, autonomy, feedback, task identity and task significance. The degree to which a job is designed to allow the said characteristics influence the employee's behaviours and motivation levels. Other scholars who have examined the concept of work characteristics appear to either concur or slightly modify the job characteristics theory concepts.

This study concentrates on only two dimensions of work characteristics, namely, task autonomy and task complexity, which mainly influence the decision-making process of an employee when executing his or her duties.

Task autonomy is viewed as one way of designing a job entailing degree to which an employee has discretion as to how to do his or her task (Langfred \& Moye, 2004). A job that accords an employee a high degree of autonomy gives him or her freedom to schedule his or her work. Notably, task autonomy is more specific than job autonomy for it includes freedom like scheduling their work and determining the path they take to carry out the work. In a school set-up, autonomy would, for instance, entail allowing the teachers to decide on how they would execute their teaching role once the time tables and teaching load allocation has been performed. Such a design is mainly informed by the view that either the employees are considered to be competent enough and they know exactly what it takes to carry out their duty, or the end products are more important than the process. It has been observed that where autonomy has been granted, employees are more likely to perform well and derive happiness out of their work (Searle \& Parker, 2013).

Task complexity, on the other hand, refers to the degree of easiness or difficulty of a given task or work (Ghitulescu, 2006). Authors contributing to this debate, such as Campbell (1998), argue that task complexity can be viewed from two perspectives of objective and subjective complexity. Subjective complexity is formed in an individual's mind where he or she perceives a given job as either easy or complicated. Objective complexity, on the other hand, is viewed as an actual evidence of a job that is being complicated in such terms as there were multiple potential ways to arrive at a desired end-state, where there is a possibility of multiple outcomes, conflicting interdependence among paths to multiple outcomes, and uncertainty of paths and outcomes (Li \& Belkin, 2008). Other contributors such as Lee and Rao (2009), argue that a complex job is one that is comprised of a high degree ambiguity and uncertainty involving tasks. Further, the concept can mean the level of unfamiliarity and complicatedness (Gill, 2012).

Of interest in this study, is to examine how job contents and design influence employees to pro-social rule breaking. Teachers in many Ugandan private secondary schools operate in an environment that is sometimes very demanding. There are sometimes no adequate supplies such as the laboratory resources, working hours being adjusted and also close supervision by the managing teams and also students. Regardless of the condition, they are expected to show results based on students' performance, especially in national exams. This is despite the fact that success in an exam is a contribution of various factors, which may not be within the teachers' control (Naluwemba et al., 2015). The teachers are therefore comparable to football coaches who have to take final responsibility for the performance of the team. That being the case, it is interesting to find out how such a condition may affect the decisions they make.

One of the notable arguments that has been advanced is that job complexity motivates people to break some of the rules and therefore can be considered to be a key antecedent of pro-social rule breaking. In this respect, Marcus and Schuler (2004) argued that at times the job may be demanding in such terms as requiring an employee to produce much with little official support or even much within a short time. In order to accomplish such tasks, an employee may decide to ignore some procedures or policies as this would be a shortcut to have the work completed. From that view, we can argue that because the concept of job complexity entails a lot of non-clear approaches and possibility of different outcomes, so does the employee attempt to approach the task differently, which may mean deliberately ignoring some norms or procedures. However, when the task is straightforward, an employee is less likely to adopt creative measures and therefore not much of a motivation to break the laid down rules, procedures and norms. Thus, we also would expect that the more complex a job is, the more employees are likely to exhibit pro-social rule-breaking behaviours.

There is further evidence from various studies that work characteristic predicts pro-social rule breaking among the employees. One such study was conducted earlier in 1986 by Brief and Motoridro. In that study, the scholars examined a wide range of pro-social organisational behaviours among them, defying rules for the sake of the benefit of the organisation, which forms part of pro-social rule-breaking concept. Among the antecedents identified was the contextual and job related. Contextual factors included job complexity and ambiguity. As such, we can infer that there is justification that work characteristics such as work complexity can motivate employees to occasionally break the rules in a bid to achieve better outcomes.

Dahlin et al. (2010) also attempted to examine the antecedents and consequences of pro-social rule breaking. In one of the hypotheses, the nature of a task, especially ambiguity, which is a key characteristic of task complexity, was advanced as an antecedent of pro-social rule breaking. This was backed by the view that in a bid to reduce the role conflict emerging from the ambiguity, the employees would be motivated to break some of the rules. Their study pitted 179 respondents in the USA, and although the results did not show a significant relationship, the relationship between the two variables was positive. 
In another study that employed the theory of reasoned action, it emerged that job demands that entailed job complexity were vital for pro-social rule breaking (Dahling, Chau \& Gregory, 2012). In explaining the outcome, it was advanced that a person may, for the sake of fulfilling a task that is not clear, opt to break rules, which otherwise, would have been difficult to accomplish if all the prescribed rules were followed.

As regards how autonomy, another work characteristic, enhances pro-social rule breaking, studies such as the one conducted by Morrison 2006, provide empirical evidence. The study showed that individuals with high level of autonomy feel that they have control over their work, and as such, they feel entitled to do what it takes, including deviating from set rules to do their work. Thus, people whose work give them a high degree of autonomy are also likely to exhibit pro-social rule-breaking behaviours.

\section{The moderating effect of risk propensity and work characteristics on pro-social rule breaking}

A moderating variable is either qualitative, which may include sex, race or such related, or quantitative for instance the salary level that affects the direction or the strength of a relationship between the independent variable and a dependent variable (Baron \& Kelly, 1986). In this study, it is advanced that risk propensity among teachers will affect the relationship between work characteristics and pro-social rule breaking.

The empirical studies that have examined risk propensity as a moderator of the relationship between work characteristics, and pro-social rule breaking are sparse. However, the available literature suggests that such a relationship is possible. For instance, a close examination of the definition of pro-social rule breaking provides a valid reason to advance an argument that risk propensity would act as a moderator. The definition indicates that pro-social rule breaking is a deliberate act made consciously (Morrison, 2006). This means that a person breaks the rules knowingly. Because there are differences in the rate at which different people display such a behaviour (Searle, 2011), one can deduce that other person-specific variables, including risk propensity, can explain the differences.

It has also been observed in a number of studies that people can be operating in a similar environment but demonstrate different behaviours, which are moderated by personal factors. For instance, such studies as one by Bateman and Crant in 1993, and another one by Vreugdenhil in 2012 demonstrated a situation where person-specific variables moderated a relationship between two factors, which served to explain difference in behaviours between people. Therefore, a person's risk propensity can be examined as one of such person-specific factors explaining the differences.

Further, people with a high degree of risk propensity are considered to be more positive and hopeful that whenever they engage in an act, decision or behaviour the end result would be positive. On the other hand, people with low level of risk propensity are very cautious about the decision they make. In such a situation even when operating in the same environment and being faced with the same opportunities and challenges, a relationship between work characteristics and pro-social rule breaking may be affected by the individual's level of risk propensity (Nicholson et al., 2002). That being the case then risk propensity would qualify to be a moderating variable.

In another study the results showed that work characteristics influenced an individual's pro-social rule-breaking tendency, it was also found that risk propensity was among the factors that moderated the relationship. The other factors that acted as moderators included personality, risk propensity and gender (Morrison, 2006). In particular, it was revealed that people with a high degree of risk propensity, given the work characteristics, demonstrated high levels of pro-social rule breaking.

From the above literature, three hypotheses can be made, namely:

- Risk propensity is positively related to pro-social rule breaking.

- Work characteristics are positively related to pro-social rule breaking.

- Risk propensity moderates the relationship between work characteristics and pro-social rule breaking.

\section{Hypothesised model}

The summary of the hypotheses, indicating the different variables is indicated in Figure 1.

\section{Research method Research design}

A cross-sectional design that entails collecting data once and no repeat is made (Bryman \& Bell, 2003) was used for the purpose of this work. Such a design, therefore, gives a snapshot of a sample of a population at a single point in time (Weerasekera, 2003). It was employed because of the advantage of having data obtained fast and also the resources in terms of time and finances committed for this study.

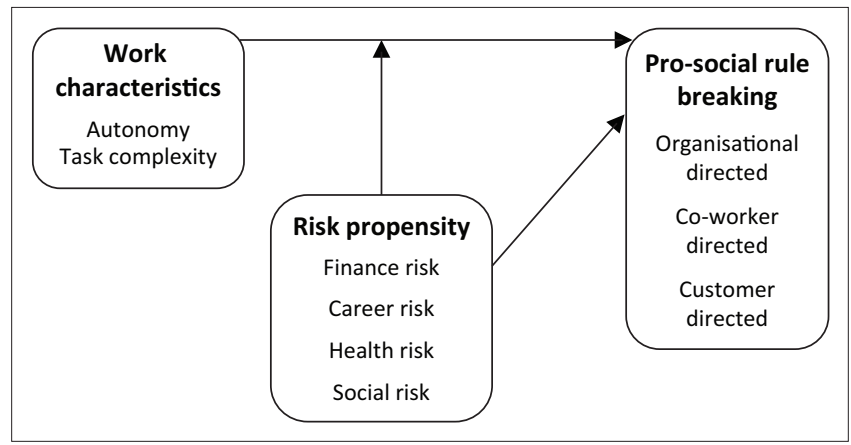

Source: Bateman and Crant 1993; Brief and Motowidlo 1986; Marcus and Schuler 2004 Morrison 2006.

FIGURE 1: Hypothesised model developed after literature review. 


\section{Research approach}

A quantitative approach, which is a systematic, objective approach that involves collection of data that can be statistically analysed was employed for the purpose of this study. This is a popular approach when attempting to answer questions that seek to establish relationships between variables, test theories and hypothesis (Maxwell, 2012). It is suitable for large sample size, and its results are ordinarily generalisable to the population and because the aim of this study was to have the results generalised, this approach was deemed appropriate. Data were collected using questionnaires, which were distributed to the selected respondents and collected after 2 weeks as agreed.

\section{Study population}

The population for this study included 630 teachers from the 15 selected schools in Wakiso District, Uganda.

\section{Sampling design \\ Sampling method}

The schools were selected based on the nine sub-county levels in Mityana District. Each sub-county had a private secondary school. The other six schools were randomly picked given the fact that some sub-counties had more schools than others. To obtain the respondents, on the other hand, stratified random sampling techniques were employed. This involved developing strata to ensure that each school represented was accorded a proportional share of the questionnaires.

\section{Sample size}

The actual sample size was determined using the Krejcie and Morgan (1970) table. The table indicates that for a population size of 630, the appropriate sample size is 242 and this formed the targeted sample. Table 1 shows the number of schools and the number of questionnaires distributed to each of the schools.

Of the 242 questionnaires that were distributed, 221 were retrieved, and upon crosschecking, 210 were deemed appropriate for the analysis, representing approximately $87 \%$ of the targeted respondents. The male participants formed the majority of the respondents to this study, forming approximately $62 \%$ of the respondents. The number of participants who were either married or single was equal. In terms of age, the majority of the participants were between the ages of 20 and 40 years. This category of participants formed approximately $84 \%$ of all the participants. The majority of the participants in this study had either an ordinary diploma $(23.33 \%)$ or a bachelor's degree $(55.71 \%)$. The participants for this study were fairly represented in all the years considered, especially from 2 years onwards. The summary is provided in Table 2 .

\section{Measurement of variables}

The questionnaire used for the purpose of this study contained sentences and respective choices where the respondents were required to respond to anchoring their answers on a five-point Likert scale, such that $1=$ Strongly Disagree and 5 = Strongly Agree.

To measure work characteristics, the questions were developed borrowing from the works of Ghitulescu (2006) and Hackman and Oldham (1976).

To measure risk propensity, questions were adopted from the work of Groves and Păunensu (2008) who examined the variable.

Finally, a questionnaire was developed from the work of Dahling et al. (2012) to measure pro-social rule breaking.

TABLE 1: A list of participating schools and the sample of teachers selected.

\begin{tabular}{lcc}
\hline School name & Total number of teachers & Sample size \\
\hline Buloba High & 92 & 35 \\
Onwards and Upwards Sec. & 51 & 20 \\
Buloba Sec. & 52 & 20 \\
St Francis College & 57 & 22 \\
St. Theresa Sec. & 38 & 15 \\
God Cares Sec & 20 & 8 \\
Kawempe Royal Sec. & 30 & 12 \\
St. James Sec & 25 & 10 \\
Bright Future Sec & 33 & 13 \\
Bulenga Sec & 39 & 15 \\
Kikaya Senior Sec & 35 & 13 \\
Bulenga Light College & 51 & 20 \\
Ebenezer Sec. & 38 & 15 \\
Bright Future Academy & 29 & 11 \\
St Elizabeth Nkoowe & 40 & 15 \\
\hline Total & $\mathbf{6 3 0}$ & $\mathbf{2 4 2}$ \\
\hline
\end{tabular}

Source: Wakiso District Education Board (2014). Updated list of Schools in Wakiso District. Wakiso, Uganda: Wakiso District Board

$\mathrm{Sec}$, Secondary school

TABLE 2: The summary of descriptive characteristics of the respondents.

\begin{tabular}{|c|c|c|c|}
\hline Descriptive characteristics & Variable & Frequency & $\%$ \\
\hline \multirow[t]{3}{*}{ Gender of the respondent } & Male & 131 & 62.38 \\
\hline & Female & 79 & 37.62 \\
\hline & Total & 210 & 100 \\
\hline \multirow{3}{*}{$\begin{array}{l}\text { Marital status of the } \\
\text { respondent }\end{array}$} & Single & 105 & 50 \\
\hline & Married & 105 & 50 \\
\hline & Total & 210 & 100 \\
\hline \multirow[t]{6}{*}{ Age of the respondent } & $20-29$ & 79 & 37.62 \\
\hline & $30-39$ & 98 & 46.67 \\
\hline & $40-49$ & 26 & 12.38 \\
\hline & $50-59$ & 5 & 2.38 \\
\hline & 60 and above & 2 & 0.95 \\
\hline & Total & 210 & 100 \\
\hline \multirow{6}{*}{$\begin{array}{l}\text { Education background of } \\
\text { the respondent }\end{array}$} & Certificate & 11 & 5.24 \\
\hline & Ordinary diploma & 49 & 23.33 \\
\hline & Bachelor's degree & 117 & 55.71 \\
\hline & Postgraduate diploma & 20 & 9.52 \\
\hline & Master's degree & 13 & 6.19 \\
\hline & Total & 210 & 100 \\
\hline \multirow{7}{*}{$\begin{array}{l}\text { Years of service of the } \\
\text { respondent }\end{array}$} & Less than 1 year & 18 & 8.57 \\
\hline & $1-2$ years & 22 & 10.48 \\
\hline & $3-4$ years & 36 & 17.14 \\
\hline & $4-6$ years & 42 & 20 \\
\hline & $8-10$ years & 63 & 30 \\
\hline & 10 years and above & 29 & 13.81 \\
\hline & Total & 210 & 100 \\
\hline
\end{tabular}




\section{Reliability analysis}

Reliability refers to the consistency and the stability of the test results. In essence, a reliable instrument is one that allows a group of respondents the same questionnaire many times to respond with consistency. To ensure this, and to retain the questions that score above 0.7 Cronbach's alpha (Nunnally, 1978), a reliability analysis of the questionnaire by using Cronbach's alpha coefficient was carried out. The results are shown in Table 3.

\section{Data analysis procedure}

The data analysis was performed by using Statistical Package for Social Sciences. The analyses conducted included the means and hierarchical regression.

\section{Ethical considerations}

Ethical principles expected of a researcher when conducting a study (Shamoo \& Resnik, 2009) were adhered throughout the study. The principles require that a study should be conducted with utmost regard to high professional and ethical standards. In particular, a copy of introduction letter was sought, which described the nature of the study and also the recruitment of respondents on voluntary basis. The distribution of questionnaire involved handing the questionnaire to the respondent and allowing them a period of 2 weeks when researchers again picked the questionnaire and randomly inserting them to the various envelopes which ensured that anonymity was guaranteed.

\section{Research findings Regression analysis}

A hierarchical regression analysis was performed to examine the contribution of independent variables in explaining the dependent variable. It was also used to test for the moderating effect of risk propensity on the relationship between work characteristics and pro-social rule breaking.

In conducting this analysis, each predictor variable was entered and its contribution towards explaining the dependent variable was examined. In Step 1, work characteristics were entered as an independent variable. The result indicated that work characteristics explained $20.4 \%(\mathrm{R} 2=0.204)$ variance in pro-social rule breaking. The beta values were also positive and the model was significant $(\beta=0.54, p<0.05)$.

In Step 2, risk propensity was added, the results remained the same and therefore no change in R2 was registered (R2 change $=0.00$ ). This means that on its own, risk propensity did not explain variation in pro-social rule breaking. The contribution was also not significant $(\beta=0.017, p>0.05)$.

TABLE 3: Reliability analysis.

\begin{tabular}{llc}
\hline Variable & $\boldsymbol{N}$ & Cronbach's Alpha \\
\hline Pro-social rule breaking & 19 & 0.926 \\
Risk propensity & 21 & 0.699 \\
Work characteristics & 22 & 0.737 \\
\hline
\end{tabular}

In Step 3, the moderation (work characteristics and risk propensity means) was added. The results indicated that there was no change in R2 (R2 change $=0.00)$. The relationship was also not significant $(\beta=0.187, p>0.05)$. This shows that there is no significant moderation between risk propensity on the relationship between work characteristics and pro-social rule breaking. Hypothesis 3, which had stated that risk propensity moderates the relationship between work characteristics and pro-social rule breaking, was therefore rejected.

Therefore, on the basis of the regression results, it was concluded that the results did not show the existence of a moderating effect of risk propensity on the relationship between work characteristics and pro-social rule breaking and thus there was no need to plot the moderation graph. The summary of the regression results is shown in Table 4.

\section{Discussion}

\section{Work characteristics and pro-social rule breaking}

This study aimed at examining the relationship between work characteristics and pro-social rule breaking, the relationship between risk propensity and pro-social rule breaking and finally the moderating effect of risk propensity on the relationship between work characteristics and prosocial rule breaking, in particular, the applicability of prospect theory and job characteristics theory in influencing the behaviour of employees at work.

The result showed that work characteristics were a good predictor of pro-social rule breaking. This means that, where work inculcates autonomy principle, the employees demonstrated a tendency to break rules that when broken, makes them execute their work more efficiently, make the services offered to the customers better and even enable them help their co-workers. In particular, the results, as expected, show that when the teachers are given high levels of autonomy they would break the rules if such breaking makes their teaching jobs more effectively. Similar results have been found in different contexts, where for instance, it has been previously found that individuals with high level of autonomy feel that they have control over how to accomplish their work activities and achieve organisational objectives

TABLE 4: Hierarchical regression results $(N=210)$.

\begin{tabular}{lccc}
\hline Variables & \multicolumn{3}{c}{ Dependent variable: pro-social rule breaking } \\
\cline { 2 - 4 } & Model 1 & Model 2 & Model 3 \\
\hline Constant & 0.56 & 0.51 & -0.14 \\
Work characteristics (main effect) $\dagger$ & $0.54 *$ & - & 0.54 \\
Risk propensity (moderator) $\dagger$ & - & 0.017 & 0.15 \\
Moderation (WorkcXRiskp) $§$ & - & - & 0.187 \\
$R^{2}$ & 0.204 & 0.204 & 0.205 \\
$R^{2}$ change & - & 0.000 & 0.000 \\
$F$ change & $53.37^{*}$ & $0.69 *$ & $0.66 *$ \\
\hline
\end{tabular}

*, Correlation is significant at the 0.01 level (2-tailed).

$\dagger$ Predictors: (constant), work characteristics; $\$$, Predictors: (constant), work characteristics, risk propensity; $\S$, Predictors: (constant), work characteristics, risk propensity, WorkcXRiskp. Note: Dependent variable: pro-social rule breaking. 
and therefore can easily deviate from the set rules if this enables them to perform better (Morrison, 2006), which supports the principles underlying job characteristics theory (Hackman,\& Oldham 1976).

Similarly, the results also showed that the teachers whose work is complex in such terms as, being assigned unfamiliar tasks, being assigned tasks they have not performed before and being assigned tasks whose outcomes cannot be clearly predetermined, they tended to pro-socially break some rules to enable them to perform. Again, as expected, the results demonstrate what has been found in other studies conducted elsewhere. For instance, an earlier study by Brief and Motowidlo (1996) found that some contextual characteristics such as job complexity and ambiguity encourage defying rules for the sake of the benefit of the organisation. Similar observations were made by Marcus and Schuler (2004) who argued that at times the job may be too demanding and this may prompt the employees to ignore some procedures or policies if by doing so would be a shortcut to have the work succeeded. Dahlin et al. (2010) also found that ambiguity, a key characteristic of task complexity, enhances pro-social rule breaking, especially in a bid to reduce the conflict emerging from the ambiguity. Again Dahling et al. (2012) observed that job demands which would entail the job complexity are vital for pro-social rule breaking because a person for the sake of fulfilling a task that is not clear may opt to break the rules.

The findings provided a weak evidence that showed that the employees who demonstrate high level of risk propensity also demonstrated tendencies to break rules, which when broken positively enhances their work performance but failed to show statistical evidence in the regression results. In particular, the teachers who viewed that they normally take risks in such terms as financial, career, health and social risks exhibited more tendencies of breaking the rules that appear to stand on their way when performing their work. This was contrary to the expected outcome that what higher risk propensity as in accordance to the prospect theory entails a person taking a bold move to do what others may not do for they have a strong hope that the outcome would be in their favour.

The probable reason related to the weak relationship however would be that, because the teachers examined in this study are from private schools, and in the Ugandan context, the proprietors have a high say, and given the reluctance of our country to enforce the employment act, such as related to appointment letters and a normal process of terminating an employee, such teachers decline to take risks and if they do, they take at a limited rate where no much harm would be expected (Sekayizi, 2013). Another possible reason is that because the risks examined involve career and financial risks, and given the current levels of unemployment, one may not be willing to take higher levels of such risks. Therefore, it can be a good reason why many respondents may have failed to take risks.
The above findings appear to deviate from the previous studies that have shown that the degree of risk propensity explains why some employees are engaged in pro-social rule breaking more than others. Morrison (2006) for example found that risk propensity was important in predicting prosocial rule-breaking behaviours. Similarly, Di Mauro et al. (2011), who employed prospect theory, observed that some job categories such as salesperson, and whose earnings rely on their contribution, tend to demonstrate high levels of risk propensity, which easily prompts them to defy some set rules in order to perform better such as to advance customer service in order to attract and retain more customers.

Further, Block et al. (2009) argued that risk takers demonstrate such behaviours as being creative and trying to come up with means and methods of improving performance, and this may entail deviating from the expected norms, which include pro-social rule breaking. Hentschke (2005) also related risk propensity to behaviours that break rules that stand on people's progress. Further still, Alshut (2014) argued that entrepreneurial leaders, a concept associated with risk taking, are known to demonstrate tendencies of considered acting against the established norms but for the better of the organisation, which is a demonstration of prosocial rule breaking.

The findings also failed to show that there was some influence of risk propensity on the relationship between work characteristics and pro-social rule breaking. This was a deviation from the expectation that employees whose jobs were designed as to allow more autonomy or whose jobs were complex would demonstrate higher tendencies of prosocial rule breaking. This was again contrary to what was expected in this study that personal differences would explain a difference with the rate at which individuals engaged in a certain behaviour, in this case, pro-social rule breaking. The above findings are a deviation from the so far available literature that suggests such a possibility. For instance the study by Morrison (2006) had found that work characteristics were a good predictor of pro-social rule breaking and were also found to be influenced by other factors such as personality, risk propensity and gender (Morrison, 2006). Also giving a reasonable ground to believe that risk propensity would have been expected to moderate relationship between work characteristics and pro-social rule breaking is the reasoning that differences in behaviours have been recorded even where people operate in a similar work environment (Bateman \& Crant, 1993; Searle, 2011; Vreugdenhil, 2012), and therefore explanations on individual differences such as risk propensity levels have been used to explain such a variation.

\section{Recommendations}

The leadership and supervisors placed in charge of running the schools should be observant of the members' behaviours, especially in regard to breaking the set rules. If they discover that a given rule is continuously broken in order to improve performance, they may obtain an indication that such a rule is no longer useful or they flex the rule. 
The leaders should also design their jobs in such a way that they offer more autonomy to the teachers. This may for instance mean that, when the performance goals have been agreed upon, the teachers should be allowed the discretion to devise their own means of achieving goals. This may be useful because teachers may think out of the box as to which better way they can do to help the school, which may entail breaking some rules that are not useful at a given circumstances.

The leaders should adopt leadership practices that allow employees to think out of the box because when left on their own, such employees may decide to do what they deem best for the organisation even if it means breaking some rules that may not be beneficial.

Furthermore, this study may suggest that school management should be made aware of the importance of their behaviour and should be encouraged to show more autonomoussupportive behaviour towards their teaching staff.

\section{Conclusion}

This study sought to examine the concept of pro-social rule breaking in the Ugandan context. The results support some of the findings in the previous study. It was found that work design that allows people autonomy and also the level of risk propensity are a good predictor of pro-social rule breaking. This, therefore, advances other studies that had found similar results in other parts of the world.

An interesting result that deviates from the expectation was also found, whereby risk propensity was not found to be a moderator of the relationship between work characteristics and pro-social rule breaking. This leads to the conclusion that people working in a similar environment were not found to have differences on their level of pro-social rule behaviours based on their levels of risk propensity, although on their own its right risk propensity promotes pro-social rule breaking. This raises the question as to whether it was only in the specific study or similar results would be witnessed in other parts of the country. Because similar studies are very sparse in the current literature on pro-social rule breaking, it might take time to confirm this study's findings with supportive research performed in similar contexts.

\section{Study limitations and future research opportunities}

This study adopted a cross-sectional study design. While this design was appropriate given the projected time and resources, the findings of the study are just based on a snapshot. As such, the study was not comprehensive enough because the possible changes in respondents' views were not incorporated. This may partly explain why some of the results have deviated from the studies conducted elsewhere.

The use of only one approach, the quantitative, where the participants were only restricted to pre-set answers cannot be considered to offer a comprehensive result, is also a limitation.
Had other approaches, including qualitative, been incorporated, more insight would have been achieved. This would have incorporated teachers' own personal accounts of what prompts them to be engaged in pro-social rule breaking.

Future researchers have an opportunity to carry out a similar study among private teachers in other Ugandan districts and also in government schools. This may expound the concept of pro-social rule-breaking behaviour, providing a contextual comparison.

There is also an opportunity to conduct a similar study by employing a longitudinal study design. Because the design involves repeat studies, it gives more comprehensive results.

Finally, a similar study can be conducted elsewhere to examine whether risk propensity would be a moderating variable between work characteristics and pro-social rule breaking.

\section{Acknowledgements Competing interests}

The preparation of this work received no funding, and there were no competing interests.

\section{Authors' contributions}

W.I. reviewed the literature and wrote the article. K.M. performed the analysis and interpretation. N.M. carried out data collection and contributed to the writing of this article.

\section{References}

Afshar, H.S., \& Doosti, M. (2015). Investigating the impact of job satisfaction/ dissatisfaction on Iranian English teachers' job performance. Iranian Journal of Language Teaching Research, 4(1), 97-115.

Alshut, J. (2014). Entrepreneurial leadership: What specific leadership behaviors encourage risk taking in employees? University of Twente. Retrieved February 13, 2015, from http://essay.utwente.nl/65313/1/Alshut_BA_MB.pdf

Armstrong, M., \& Taylor, S. (2012). Armstrong's handbook of human resource practice. (13th edn.). Retrieved May 23, 2015, from https://otgo.tehran.ir/Portals/0/pdf/ Armstrong's $\% 20 \mathrm{Handbook} \% 20$ of $\% 20$ Human $\% 20$ Resource $\% 20$ Management $\% 20$ Practice_1.pdf

Baron, R.M., \& Kenny, D.A. (1986). The moderator-mediator variable distinction in social psychological research: Conceptual, strategic, and statistical considerations. Journal of Personality and Social Psychology, 51, 1173-1182. https://doi org/10.1037/0022-3514.51.6.1173

Bateman, T.S., \& Crant, J.M. (1993). The proactive component of organizational behavior. Journal of Organizational Behavior, 14(2), 103-118. https://doi. org/10.1002/job.4030140202

Block, J.H.P., Sandner, P., \& Spiegel, F. (2009). Do risk attitudes differ within the group of entrepreneurs? MPRA Paper, University of Munich, Munich, Germany.

Brief, P., \& Motowidlo, S.J. (1986). Prosocial organizational behaviors. The Academy of Management Review, 11(4), 710-725.

Bryant, P.C., Davis, C.A., Hancock, J.I., \& Vardaman, J.M. (2010). When rule makers become rule breakers: Employee level outcomes of managerial pro-social rule breaking. Employee Responsibilities and Rights Journal, 22(2), 101-112. https:// breaking. Employee Responsibilities and
doi.org/10.1007/s10672-009-9114-6

Bryman, A., \& Bell, E. (2003). Business research methods. New York: Oxford University Press.

Campbell, J.P. (1998). Modelling the performance prediction problem in industrial and organizational psychology. In M. Dunnette \& L.M. Hough (Eds.), Handbook of industrial and organizational psychology (2nd ed., Vol. 1, pp. 687-732). Palo Alto, CA: Consulting Psychologists Press.

Caza, A., \& Cameron, K.S. (2008). Positive organizational scholarship: What does it achieve? In C.L. Cooper \& S. Clegg (Eds.), The Sage handbook of organizational behavior: Macro approaches (Vol. 2, pp. 99-116). Thousand Oaks, CA: Sage.

Dahlin, E., Neely, A.S., Larsson, A., Bäckman, L., \& Nyberg, L. (2010). Transfer of learning after updating training mediated by the striatum. Journal of Science, 320 1510-1512. 
Dahling, J.J., Chau, S.L., Mayer, D.M., \& Gregory, J.B. (2012). Breaking rules for the right reasons? An investigation of pro-social rule breaking. Journal of right reasons? An investigation of pro-social rule breaking.
Organizational Behavior, 33, 21-42. https://doi.org/10.1002/job.730

Di Mauro, M., Lumbroso, D., \& Tagg, A. (2011). Agent-based modeling to inform flood emergency planning and management. Journal of Emerging Management, 9, (1), 71-79.

Ghitulescu, B.E. (2006). Shaping asks and relationships at work: Examining the antecedents and consequences of employee job crafting. Unpublished doctora dissertation, University of Pittsburgh, Pittsburgh.

Gill, G. (2012). My research: What is task complexity? Retrieved March 23, 2015, from http://grandon.com/blog/?p=162

Groves, K., \& Păunescu, C. (2008). Examining the antecedents and outcomes of Romanian entrepreneurial orientation. Management \& Marketing, 3(11), 3-18.

Hackman, J.R., \& Oldham, G.R. (1976). Motivation through the design of work: Test of a theory. Organizational Behavior and Human Performance, 16, 250-279. https:// doi.org/10.1016/0030-5073(76)90016-7

Hentschke, G.C. (2005). The essentials of school leadership, Chapter 8: Entrepreneurial leadership. London: Corwin Press.

Kahneman, D., \& Tversky, A. (1979). Prospect theory: An analysis of decision unde risk. Econometrica 47(2), 263-292. https://doi.org/10.2307/1914185

Krejcie, P. \& Morgan, D.W. (1970). Determining sample size for research activities Educational and Psychological Measurement, 30(3), 607-610. https://doi. org/10.1177/001316447003000308

Langfred, C.W., \& Moye, N.A. (2004). Effects of task autonomy on performance: An extended model considering motivational, informational and structura mechanisms. Journal of Applied Psychology, 89(6), 934-945. https://doi. org/10.1037/0021-9010.89.6.934

Lee, J., \& Rao, H.R. (2009). Task complexity and different decision criteria for online service acceptance: A comparison of two e-government compliance service domains. European Journal of Information Systems, 18, 106-125. https://doi. org/10.1016/j.dss.2009.04.009

$\mathrm{Li}, \mathrm{Y}$, \& Belkin, N.J. (2008). A faceted approach to conceptualizing tasks in information seeking. IP\&M, 44(6), 1822-1837. https://doi.org/10.1016/j.ipm.2008.07.005

Marcus, B., \& Schuler, H. (2004). Antecedents of counterproductive behavior at work: A general perspective. Journal of Applied Psychology, 89, 647-660. https://doi. org/10.1037/0021-9010.89.4.647

Maxwell, J.A. (2012). What is realism, and why should qualitative researchers care? In J.A. Maxwell (Ed.), A realist approach for qualitative research (pp. 3-13). Thousand Oaks, CA: Sage.

Morrison, E.W. (2006). Doing the job well: An investigation of pro-social rule breaking. Journal of Management, 32, 5-28. https://doi.org/10.1177/0149 206305277790
Naluwemba, F., Sekiwu, D., \& Okwenje, V. (2015). The interplay of school welfare provision and teacher performance: The case of Ugandan secondary schools. International Journal of Educational Policy Research and Review, 3(1), 6-13.

Nicholson, N., Frenton-O'Creevy, M., Soane, E. \& Willman, P. (2002). Risk propensity and personality. London Business School Working Paper, London.

Nunnally, J.C. (1978). Psychometric theory. (2nd edn.). New York: McGraw-Hill.

Phil, C., Bryant, P.C., Davis, C.A, Hancock, J.I., \& Vardaman, J.M. (2010). When rule makers become rule breakers: Employee level outcomes of managerial pro-social
rule breaking. Employee Responsibilities and Rights Journal, 22, 101-112. https:// rule breaking. Employee Responsibilitites
doi.org/10.1007/s10672-009-9114-6

Rothmann, S. \& Welsh, C. (2013). Employee engagement in Namibia: The role of psychological conditions. Management Dynamics, 22(1), 14-25.

Searle, B.J., \& Parker, S.K. (2013). Work design and happiness: An active, reciprocal perspective. In S.A. David, I. Boniwell, \& A. Conley Ayers (Eds.), Oxford Handbook of Happiness (pp. 711-732). Oxford: Oxford University Press.

Searle, J.R. (2011). Making the social world: The structure of human civilization. Oxford: Oxford University Press, $224 \mathrm{p}$.

Sekiyivu, J. (2013). Challenges/dilemmas of private secondary school management case of selected schools in Mukono District. Retrieved October 25, 2016, from https://brage.bibsys.no/xmlui/handle/11250/172031

Sitkin, S.B. \& Pablo, A.L. (1992). Reconceptualizing the determinants of risk behaviour. Academy of Management Review, 17, 9-39.

Ssanyu, R. (2013). Social protection in Uganda: What is the role of a minimum wage? DRT Research report. Unpublished.

Uganda Ministry of Educations and Sports. (2014). Teacher issues in Uganda: A diagnosis for a shared vision on issues and the designing of a feasible, indigenous and effective teachers' policy. Retrieved October 27, 2016, from http://

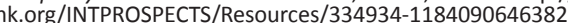
Rep-of-Uganda-2014-Ugandas-Employment-Challenge.pdf

Vardaman, J.M., Gondo, M.B., \& Allen, D.G. (2014). Ethical climate and pro-social rule breaking in the workplace. Human Resource Management Review, 24, 108-118. https://doi.org/10.1016/j.hrmr.2012.05.001

Vreugdenhil, H. (2012). Do older employees use task crafting in order to reduce the perceived misfit with their job? Master thesis Human Resource Studies, Universiteit Van Tilburg.

Wakiso District Education Board (2014). Updated list of Schools in Wakiso District. Wakiso, Uganda: Wakiso District Board.

Weerasekera, D.R. (2003). Longitudinal vs. cross-sectional analysis. University of Colombo. Retrieved May 20, 2015, from http://science.cmb.ac.lk/Departments/ Statistics/statcircle/Publications/Articles/Longitudinal.pdf

Youli, H., Xixi, L., \& Xi, W. (2014). The effects of transformational leadership on employee's pro-social rule breaking. Canadian Social Science, 10(1), 128-134. https://doi.org/10.3968/j.css.1923669720141001.4286 